\title{
Antimalarials - are they effective and safe in rheumatic disease? Focus on the neuropsychiatric side effects
}

\author{
Cirro Manzo \\ Internal and Geriatric Department, Rheumatologic Outpatient Clinic Hospital “Mariano Lauro”, Sant'Agnello, Italy
}

\section{Dear Editor,}

I read with interest the paper recently published by Haladyj et al. [1], in which the authors review, among other topics, the problems associated with the use of antimalarial drugs (AD) in patients with rheumatic diseases.

Neuropsychiatric clinical manifestations are uncommon side effects of therapy with chloroquine (CQ) or hydroxychloroquine (HCQ). These side effects are related to their ability to cross the blood-brain barrier. In the brain, they can have a tissue concentration up to 10-20 times higher than the plasmatic one [2].

A great variety of neuropsychiatric side effects have been reported due to CQ/HCQ use. They can include less severe clinical manifestations such as affect lability $(1 / 100 \leq$ frequency $<1 / 10$ for HCQ $)$ and nervousness $(1 / 1000 \leq$ frequency $<1 / 100$ for HCQ), as well as more severe conditions such as true psychosis. Depression, anxiety and sleep disorders are other common side effects. In some cases, these manifestations caused the patient's hospitalization or death. Suicidal ideation and suicide have also been reported [3].

The real incidence and prevalence of some of these manifestations are still unknown. Since 2012, the European Medicines Agency (EMA) has made publically available data on suspected adverse drug reactions for authorized medicines in the European Economic Area. Since the date of establishment of EudraVigilance, more than 1500 segnalations regarding a great variety of neuropsychiatric adverse events following therapy with HCQ and/or CQ have been recorded. However, from this database, it is not possible to get access to information on an individual level for privacy policy. Therefore, individual information such as the description of the event, the indication of use, the dosage, the concurrent drugs, and comorbidities is not available [3]. The incomplete- ness of data entered in international databases (such as EudraVigilance) represents a first critical point.

Some rheumatic diseases in themselves can cause neuropsychiatric clinical manifestations [4-6]. They seem to be caused by the presence of vasculitis, opportunistic infections, and atherosclerotic processes, which are "accelerated" in all inflammatory rheumatic diseases. Other aetiological disease-related causes are the direct activity of the disease on the central nervous system by autoantibodies, such as antiphospholipid and anti-ribosome $\mathrm{P}$ autoantibodies. The differential diagnosis between manifestations due to the rheumatic disease and CQ/HCQ side effects represents a second critical point. This point is mandatory, in order to avoid diagnostic and therapeutic mistakes.

The management of CQ/HCQ neuropsychiatric adverse events represents a third critical point. Generally, there is a complete resolution of the event after CQ/HCQ discontinuation, but due to their long half-life, neuropsychiatric adverse events may continue for several weeks. Pharmacological treatments could be considered for the more severe neuropsychiatric manifestations $[3,7,8]$.

Several possible mechanisms have been hypothesized for the onset of these adverse events.

Risk factors are better identified and are more important in clinical practice (Table I). However, CQ/HCQ neuropsychiatric adverse events can be possible even in the absence of any risk factor, such as type B adverse drug reaction in accordance with the Rawlins and Thompson classification [8, 9]. No difference between older and younger patients was found, but polypharmacology and age-related impairment of organ functions can increase the risk in older ones [3, 7].

In conclusion, even if ocular, cutaneous and gastrointestinal are well-known side effects of therapy with $\mathrm{CQ} / \mathrm{HCQ}$, as correctly highlighted by Haladyj et al., the possible occurrence of neuropsychiatric adverse events 
Table I. Risk factors of chloroquine/hydroxychloroquine-induced neuropsychiatric adverse events

\begin{tabular}{|l|}
\hline \multicolumn{1}{|c|}{ Risk factors of CQ/HCQ } \\
\hline Previous psychiatric disorders \\
\hline Family history \\
\hline Female gender \\
\hline Low body weight \\
\hline Alcohol intake \\
\hline Concomitant administration of low-dose glucocorticosteroids \\
\hline $\begin{array}{l}\text { Concomitant administration of CYP3A4 inhibitors (indinavir, nelfinavir, ritonavir, clarithromycin, } \\
\text { erythromycin, fluconazole, itraconazole, ketoconazole, amiodarone, cimetidine, diltiazem, verapamil) }\end{array}$ \\
\hline $\begin{array}{l}\text { Dose exceeding the maximum therapeutic dosage recommended for rheumatic diseases } \\
\text { (> } 6.5 \text { mg/kg/day for HCQ; }>3 \text { mg/kg/day for CQ) }\end{array}$ \\
\hline
\end{tabular}

$\mathrm{CQ}$ - chloroquine; $\mathrm{HCQ}$ - hydroxychloroquine

(even if not common) cannot be minimized. As already pointed out, more complete data should be included in the databases, respecting privacy policy. Research should be performed to provide new data to make easier the recognition of CQ/HCQ-induced neuropsychiatric clinical manifestations. Some of these, such as depression, anxiety and sleep disorders, could be not properly evaluated in patients with rheumatic diseases. Finally, paying attention to specific symptoms, especially those occurring with sudden and feeble changes in behaviour, can be useful to reduce the risk that such events will get worse.

The author declares no conflict of interest.

\section{References}

1. Haładyj E, Sikora M, Felis-Giemza A, Olesińska M. Antimalarials - are they effective and safe in rheumatic diseases? Reumatologia 2018; 56: 164-173.

2. Rynes RI. Antimalarials. In: Textbook of rheumatology, Kelley WN, Harris ED Jr, Ruddy S, Sledge CB (eds.). Saunders Company, Philadelphia 2001: 864-865.
3. Mascolo AM, Berrino PM, Gareri P, et al. Neuropsychiatric clinical manifestations in elderly patients treated with hydroxychloroquine: a review article. Inflammopharmacology 2018. doi: 10.1007/s10787-018-0498-5 [Epub ahead of print]

4. Joaquim AF, Appenzeller S. Neuropsychiatric manifestations in rheumatoid arthritis. Autoimmun Rev 2015; 14: 1116-1122.

5. Eaton WW, Byrne M, Ewald H, et al. Association of schizophrenia and autoimmune diseases: linkage of Danish national registers. Am J Psychiatry 2006; 163: 521-528.

6. Perzynska-Mazan J, Maslinska M, Gasik R. Neurological manifestations of primary Sjogren's syndrome. Reumatologia 2018; 56: 99-105.

7. Manzo C, Capuano A, Gareri P, et al. Manifestazioni neuropsichiatriche nel'anziano in corso di terapia con idrossiclorochina. Psicogeriatria 2017; 2: 77-81.

8. Manzo C, Gareri P, Castagna A. Psychomotor Agitation Following Treatment with Hydroxychloroquine. Drug Saf Case Rep 2017; 4: 6.

9. Altintas E. Hydroxychloraquine-induced acute psychotic disorder in a female patient with rheumatoid arthritis: a case report. Düşünen Adam J Psychiatry Neurol Sci 2015; 28: 369-373. 